\title{
Den nasjonale strategien for selvmordsforebygging i England: refleksjoner over erfaringer som er gjort
}

\author{
Ved Jenny Bywaters
}

\begin{abstract}
1999 satte det engelske helsedepartementet (DH) seg som mål å redusere forekomsten av selvmord og dødsfall med ukjent årsak med $20 \%$ innen 2010 (DH 1999a). I den nasjonale strategien for selvmordsforebygging i England (DH 2002) er det satt opp seks evidensbaserte målsettinger for det forebyggende arbeidet. Implementeringen av strategien er drevet fram av National Institute for Mental Health i England (NIMHE). I denne artikkelen beskriver og reflekterer forfatteren over de erfaringene som er gjort så langt. Artikkelen presenterer imidlertid ikke noen data som kan belyse hvorvidt reduksjonen i antall selvmord er et direkte resultat av den selvmordsforebyggende strategien.
\end{abstract}

\section{Selvmord i England}

Selv om selvmordsraten i England ikke er spesielt høy sammenliknet med mange andre europeiske land, er selvmord et alvorlig samfunnsproblem som medfører tap av om lag 5000 liv per år i England (DH 2002).

I 1999 satte man seg som nasjonalt mål å redusere forekomsten av selvmord og dødsfall med ukjent årsak med $20 \%$ innen 2010 (DH 1999a og DH 1999b).

Fordi det dreier seg om relativt små absolutte antall, med en uunngåelig tilfeldig variasjon fra år til år, regner man vanligvis ut gjennomsnittsrater på basis av treårsperioder. $M$ ålet er derfor å redusere selvmordsraten fra utgan gsraten på 9,2 dødsfall per 100.000 innbyggere i 1995/6/7 til 7,3 dødsfall per 100.000 innbyggere i 2009/10/11 (utregnet i henhold til Europeisk standardpopulasjon med justering for forskjeller i al dersstruktur).

Den nasjonale strategien for selvmordsforebygging i England

H ensikten med den nasjonale strategien for selvmordsforebygging i England (DH 2002) var å få til en sammenhengende og helhetlig tilnærming til selvmordsforebygging basert på fire grunnleggende prinsipper: Strategien skulle være vidtfavnende, evidensbasert, spesifikk og gjenstand for evaluering. Strategien ble utviklet gjennom en prosess der det ble innhentet informasjon fra en rådgivende ekspertgruppe og kommentarer fra en bredt sammensatt referansegruppe før den ble gjenstand for en omfattende høring. I den endelige strategien finner vi de følgende seks mål settingene:

1. Redusere sel vmordsrisikoen i viktige risikogrupper

2. Fremme psykisk helse i hele befolkningen

3. R edusere tilgangen til og dødeligheten av selvmordsmidler

4. Forbedre kvaliteten på massemedienes omtale av selvmord

5. Fremme forskning på selvmord og selvmordsforebygging

6. Bedre monitoreringen av suicidal atferd for å kunne måle framskritt i forholdet til målet om å redusere antallet selvmord som beskrevet i Saving Lives: $\mathrm{O}$ ur $\mathrm{H}$ ealthier $\mathrm{N}$ ation.

\section{Gjennomføringen av strategien}

$M$ ålsetting 1: Redusere selvmordsrisikoen i viktige risikogrupper

Det ble brukt strenge kriterier for å plukke ut de fem risikogruppene man val gte å prioritere:
Personer som behandles innen psykisk helsevern

Forskergruppen i prosjektet " $\mathrm{N}$ ational $\mathrm{C}$ onfidential Inquiry into Suicide and Homicide by people with a mental illness" utgir rapporter og anbefal inger basert på aggregerte, anonymiserte data. I de to første rapportene (A ppleby et al.,1999; A ppleby et al., 2001) listes det opp 12 punkter for en tryggere behandling. På grunnlag av disse 12 punktene ble det utviklet hjel peverktøy som gir psykiatriske avdelinger mulighet til å kontrollere sin egen praksis opp mot an befalt bestepraksis (Duffy et al., 2003). Den engelske "H ealthcare Commission", et uavhengig, lovfestet organ som overvåker tjenesteytere innen helsesektoren, tar nå også med i sin årlige vurdering av tjenesteyterne hvordan dette kontrollverktøyet brukes.

$M$ an har vist at det er stor risiko forbundet med å bruke stive stenger/skinner for oppheng av dusjforheng og gardiner på sengeavdelinger. Den engelske helsedirektøren har understreket at alle aktuelle organisasjoner tilknyttet den nasjonale helsetjenesten må eliminere denne risikoen (DH 2000), og har regelmessig sjekket om dette påbudet blir ful gt.

I den siste rapporten fra "N ational C onfidential Inquiry" trekkes det fram nye risikofaktorer som man må ta tak i. Spesielt viktig er det å se nærmere på antallet selvmord utført av pasienter som er borte fra sengeavdelinger uten lov, samt på risikoen for selvmord i de første syv dagene etter utskriving ( $\mathrm{N}$ ational Confidential Inquiry, 2006).

\section{Personer som skader seg selv}

Det er en kjent sak at personer som skader seg selv, har forhøyet risiko for senere å gjøre sel vmord ( $H$ awton et al., 2003a). "N ational Institute for Health and Clinical Excellence", som utgir evidensbaserte retningslinjer for god behandling innenfor den nasjonale helsetjenesten i England og W ales, har kommet med en veiledning for hvordan man bør behandle selvskading på akuttavdelinger (N ICE, 2004). Det er satt i verk tiltak for å sikre at "H ealthcare Commission" sjekker at denne veiledningen blir fulgt i forbindelse med sin rutinekontroll av akuttenheter.

\section{Unge menn}

I nesten 30 år steg selvmordsraten for unge menn mellom 20 og 34 år bratt mens selvmordsraten for alle innbyggere under ett holdt seg stabil eller gikk litt ned (Se figur 1 neste side). $M$ an forsto ikke helt hvorfor og visste derfor heller ikke hvilke tiltak som ville ha størst effekt. $M$ an igangsatte derfor tre statsfinansierte pilotprosjekter som skulle finne frem til tiltak for 
Figur 1: Utviklingen i selvmordsraten for unge menn i alderen 20-34 år. Rater for dødsfall som skyldes villet egenskade eller der det er usikkert om skaden er påført med hensikt, England

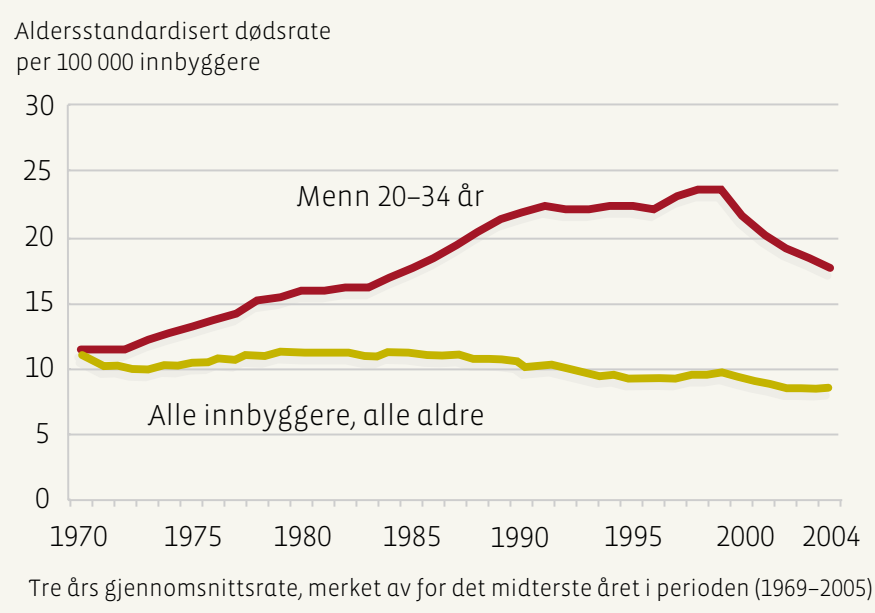

Ratene er utregnet på grunnlag av befolkningsestimater basert på manntallet for 2001 Ratene er utregnet i henhold til europeisk standardbefolkning for å ta høyde for forskjeller i aldersstruktur. For årene til og med 1998 og år 2000 er ICD9 benyttet; for 1999 og 2001 og senere er ICD10 benyttet. Kilde: ONS (ICD9 E950-E959, pluss E980-E989, unntatt E988.8 (likskue utsatt) ; ICD10 X60-X84,Y10-Y34 unntattY33.9 (venter på avgjørelse))

å fremme den psykiske helsen blant unge menn. I hvert av disse prosjektene utforsket man forskjellige måter å nå frem til unge menn på. D et var viktig å forstå deres holdninger og verdier og arbeide med dem for å finne ut hvordan tiltak for å fremme psykisk helse kunne gjøres mer tilgjengelige og akseptable. Det ble gjennomført en uavhengig evaluering av de tre prosjektene for å samle lærdom og komme med anbefalinger for videre fremstøt mot denne gruppen (N IM HE, 2006b).

\section{Innsatte i fengsler}

Fengsel svesenet satte seg sitt eget mål for forebygging av selvmord ( $20 \%$ reduksjon i selvmordsraten fra et utgangspunkt på 141 per 100.000 i 1999/2000 til 112,8 innen april 2004). En gruppe som arbeider for sikrere soningsforhold, "Safer

Figur 2: Selvmord i fengsler, England

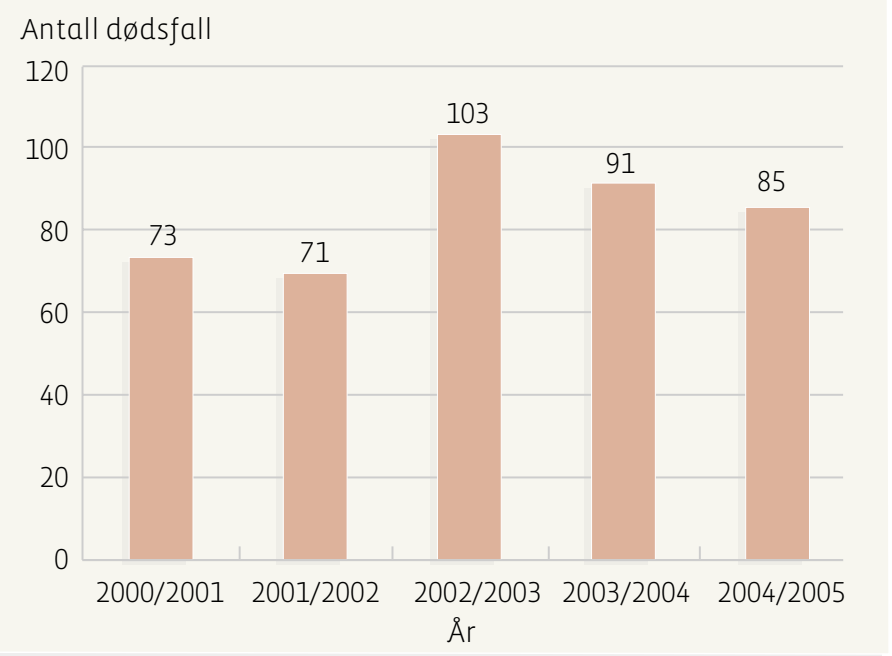

Kilde: HM Prison Service
C ustody" (www.homeoffice.gov.uk/about-us/organisation/ directorate-search/noms/ hopd/scg/), har forsøkt å ta tak i problemet på flere måter, blant annet ved å utnevne en koordinator for selvmordsforebyggende arbeid i hvert fengsel, styrke helsetjenesten for fanger, gjøre risikovurderingen ved ankomsten til fengselet bedre, opprette tryggere celler for fanger med høy risiko for å gjøre selvmord (dvs. uten gardinoppheng og med sengetøy og klær som ikke så lett kan brukes til strangulering), gi de innsatte bedre tilgang til krisetelefontjen ester som for eksempel Samaritans, få hjelp av Samaritans til å lære opp "Iyttere" blant fangene som kan gi likemannshjelp til de som strir med problemer.

Selvmordstallene blant fanger går nå ned til tross for et økende antall innsatte og stort press på grunn av overfylte fengsler (figur 2).

\section{Y rkesgrupper med høy selvmordsrisiko (gårdbrukere, leger,} sykepleiere)

H elsedepartementet har støttet utviklingen av evidensbaserte retningsl injer for helse på arbeidspl assen, med sterkt fokus på psykisk velvære på jobben, fordi psykiske helseproblemer nå er den viktigste årsaken til fravær. N I M H E fremmer selvmordsforebyggende arbeid $\mathrm{i}$ jordbrukssamfunn via frivillige organisasjoner som for eksempel "Farming $\mathrm{H}$ elp" og "R ural Stress Information N etwork".

\section{M ålsetting 2: F remme psykisk helse i hele befolkningen}

Selv om de som făr behandling innen psykisk helsevern er en høyrisikogruppe, blir $75 \%$ av alle selvmord utført av mennesker som ikke er i kontakt med det psykiske helsevernet. D erfor står behovet for å fremme den psykiske helsen i hele befolkningen sentralt i målsetting $2 \mathrm{i}$ den nasjonale strategien.

I 2005 fikk N IM H E laget M aking it Possible, en god praktisk veiledning til hvordan psykisk helse og velvære kan forbedres. Den inneholder en liste over ti prioriterte handlingsområder der det var mest sannsynlig at tiltak ville ha en effekt, og viste hvilke enkle positive handlinger alle kunne gjøre for å opprettholde sitt eget psykiske velvære (N IM HE, 2005b).

I 2006 utga regjeringen $\mathrm{O}$ ur $\mathrm{H}$ ealth, $\mathrm{O}$ ur $\mathrm{C}$ are, $\mathrm{O}$ ur Say, der den forpliktet seg til å spre informasjon ut til folket om hvordan psykisk helse og velvære kan forbedres. D ette skal man få til ved å inkludere psykisk helse i den nasjonale sosiale markedsføringsstrategien og ved å sikre at hvert område har en egen strategi for å fremme psykisk helse som er på linje med de an befalinger for bestepraksis som gis i M aking It Possible (DH 2006a).

I tillegg har det vært arbeidet spesielt med å nå de mest sårbare gruppene i befolkningen som for eksempel sosialt underprivilegerte og ekskluderte grupper, etniske minoriteter, rusmisbrukere, samt ofre for vold og seksuelt misbruk, inkludert seksuelt misbrukte barn. Inkludert er også barn og ungdom, kvinner under og etter svangerskap, eldre og etterlatte ved selvmord (DH 2006b).

N IM HE har nylig lansert et hjel peverktøy som "Primary C are Trusts" (en organisasjon innenfor den nasjonale helsetjenesten 
Figur 3: Selvmord og dødsfall med usikker årsak etter metode og kjønn, England 2005
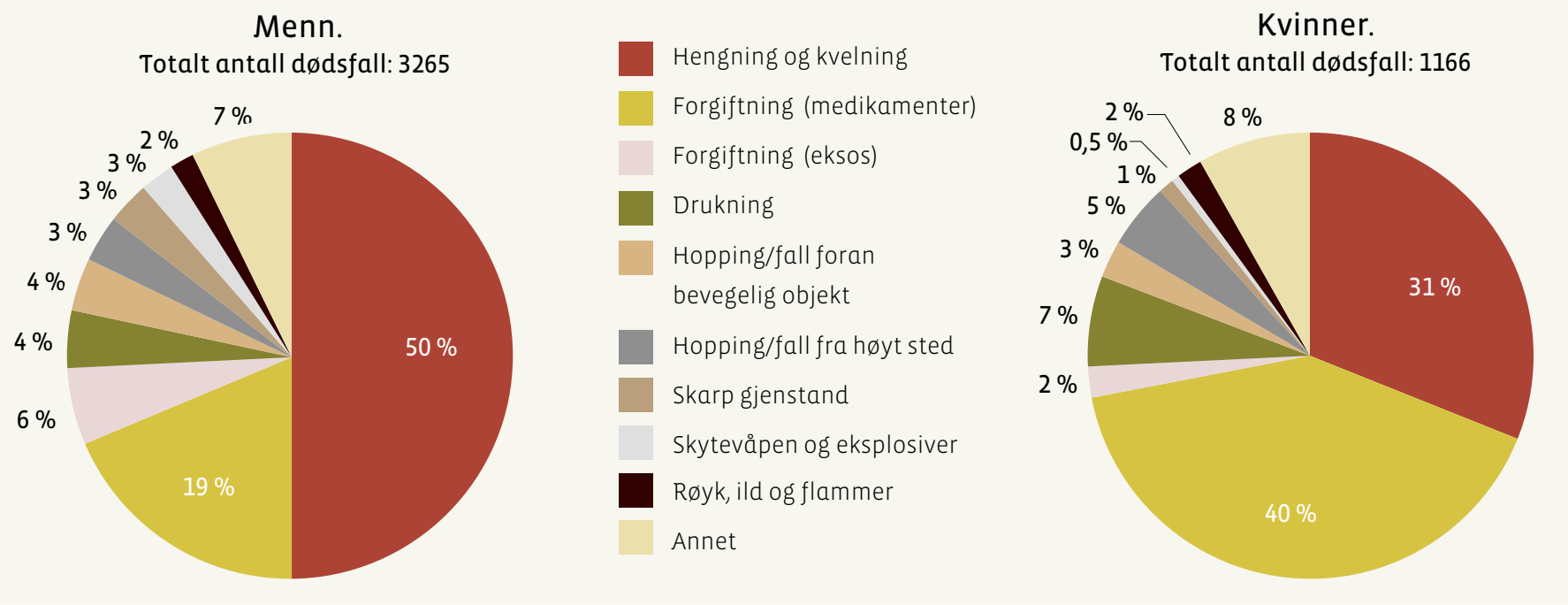

Kilde: Office for National Statistics (ONS), 2006

med ansvar for et distrikt med ca. 300.000 mennesker) kan bruke når de gjør selvmordsgjennomgang i sitt område. M ålet er å hjelpe dem med å finne måter å redusere antallet selvmord på (N IM H E, 2006c).

$M$ ålsetting 3: Redusere tilgangen til og dødeligheten av selvmordsmidler

A rbeidet med denne mål settingen bygger selvfølgelig på informasjon fra offentlig statistikk om hvilke selvmordsmidler som er hyppigst brukt (figur 3). Disse dataene viser at det er viktig for England å fokusere på:

\section{H engning og kvelning, særlig blant menn}

- Forgiftning relatert til medikamenter, særlig blant kvinner

\section{A nnen type forgiftning, inkludert eksos}

H opping og fall

Det er vanskeligå redusere tilgangen til og dødeligheten av hengning og kvelning i befolkningen i sin alminnelighet, så man har konsentrert seg om muligheten av forebygging $\mathrm{i}$ kontrollerte omgivel ser som psykiatriske avdelinger og fengsler, som beskrevet ovenfor.

Fra september 1998 ble den maksimale pakningsstørrelsen for over-disk-salg av paracetamol og aspirin redusert til 32 tabletter for apoteker og 16 tabletter for andre utsal gssteder.

$\mathrm{H}$ awton og medarbeidere (2003b) fremhevet i sin forskning farene ved coproxamol (reseptbelagt smertestillende middel en kombinasjon av dextropropoxyphene og paracetamol). D et ble fremmet en sak for "C ommittee on Safety of M edicines", og i 2005 annonserte "M edicines and H ealthcare Products Regulatory A gency" at de planla å trekke tilbake dette medikamentet fra markedet.

Dødsfall ved hopping og fall handler om både selvmord på jernbaneskinner og andre populære selvmordssteder som broer, klipper og høye bygninger. N IM H E samarbeider tett med jernbanel edelsen og ledelsen for undergrunnen i London for å redusere denne risikoen. Det er nettopp blitt publisert retningslinjer for hvordan lokale myndigheter kan identifisere populære selvmordssteder og for rel evante eviden sbaserte forebyggingstiltak (NIM HE, 2006d).

$\mathrm{M}$ ålsetting 4: F orbedre kvaliteten på massemedienes omtale av selvmord

Det finnes mange eksempler på at mediereportasjer enten kan forverre eller dempe stigmaet ved psykiske lidelser, noe som kan virke inn på om folk søker hjelp når de opplever psykiske problemer. Vi vet også at ufølsomme beskrivelser av selvmord kan øke sorgreaksjonene hos etterlatte ved selvmord, som selv er en høyrisikogruppe. $\mathrm{H}$ vis selvmordsmetoden beskrives i detalj i medieoppslaget, kan dette ha en smitteeffekt. Etter press fra organisasjoner som arbeider med selvmordsforebygging (først og fremst Samaritans) har "Press Complaints Commission" (tilsvarer Pressens faglige utvalg i N orge) nylig tilføyd følgende setning i sine retningslinjer: "W hen reporting suicide, care should be taken to avoid excessive detail about the method used" (Press C omplaints C ommission, 2006)

D et arbeides med å undersøke hvordan man best kan sikre at travle journalister og redaktører faktisk tar hen syn til slike retningslinjer. En rapport om dette vil snart bli publisert.

I det siste har Internetts rolle når det gjel der à fokusere på og beskrive konkrete selvmordsmetoder og/eller sette personer i kontakt med andre som også overveier å ta livet av seg, ført til økt bekymring i mange land. Regjeringsmedl emmer i England har engasjert seg aktivt i dette problemet. På det juridiske området er konklusjonen at muligheten for å kontrollere dette ved lovgivning er begrenset når nettstedene er lokalisert i utlandet. En alternativ tilnærming er mer lovende: Tjenesteleverandører på Internett kan hjelpe til ved å sørge for at støttefunksjoner og hjelpetjenester, som for eksempel Samaritans, kommer høyt opp på listen når man søker på selvmordsrelaterte nøkkelord, for eksempel "selvmord". 
M ålsetting 5: F remme forskning på selvmord og selvmordsforebygging

I tråd med den nasjonale strategien for selvmordsforebygging (NSPS) er det etablert et forskningsforum som skal gi råd om prioriteringer.

Staten har bevilget penger til en multisenter monitoreringsstudie av selvskading i fire engel ske byer. $\mathrm{H}$ er samles forskningsdata til hjelp for det videre arbeidet med denne høyrisikogruppen.

Det blir også forsket på forskjellige selvmordsmetoder. Det forskes videre på hvordan man kan fremme psykisk helse blant unge menn, på selvmord blant fargede og i etniske minoritetsgrupper, og på selvmord blant lesbiske, homofile og biseksuelle personer. De to sistnevnte prosjektene har demonstrert begrensningene i rutinemessig innsamlede data, og N SPS arbeider nå med å få inkludert etniske data i rettsmedisinske journaler.

$M$ ålsetting 6: B edre monitoreringen av selvmord for å kunne spore endringer som fører mot målet om å redusere antallet selvmord

Implementeringen av den nasjonale strategien monitoreres av en rådgiven de ekspertgruppe som møtes to ganger i året og gjennomgår de siste statistikkene. En rapport om utviklingen blir publisert en gang i året. Den inneholder både kvantitative data om utviklingen i retning av det nasjonale målet og kvalitative rapporter om hva som er gjort i de siste tolv månedene, og prioriteringer for de neste tolv månedene ( $\mathrm{N}$ IM HE, 2005a, 2006a). D en rådgivende ekspertgruppen søker jevnlig opp informasjon om selvmord i spesielle befolkningsgrupper ut fra alder, kjønn, yrke, selvmordssted eller selvskadingsmetode for å holde seg orientert og kunne oppdatere strategien om nødvendig.

\section{Resultater}

Den generelle trenden er at selvmordsratene i England går ned. Til og med selvmordsraten for unge menn viser en oppmuntrende nedgang etter å steget bratt en periode (figur 1). Selvmordsraten er nå lavere enn noen gang. N edgangen går imidlertid langsommere enn før, og hvis den nåværende utviklingen fortsetter, vil målet for 2010 ikke bli nådd (figur 4).

\section{Diskusjon}

Prosessen med å utvikle en nasjonal strategi med eksperthjelp fra ledende suicidologer som professorene K eith $\mathrm{H}$ awton, David G unnell og Louis A ppleby førte til at det videre arbeidet ble evidensbasert, med tydelig fokus og greit å monitorere og evaluere.

Professor A ppleby har vært en sterk leder for den rådgivende ekspertgruppen fra sin stilling som leder for det nasjonale programmet for psykisk helse, med direkte kontakt med medlemmer av regjeringen. $\mathrm{H}$ ans spesialistkunnskap i kombinasjon med hans politiske posisjon har vært svært viktig for programmets suksess.

Statistikerne i helsedepartementet, som arbeider tett sammen med det uavhen gige offentlige statistikkontoret, "O ffice for $\mathrm{N}$ ational Statistics", har kommet med stadige oppdateringer, noe som har vært til uvurderlig hjelp for å få frem hvilke områder som trenger spesiell oppmerksomhet, og for å få til en monitorering av de tiltakene som er satt i verk.

Størst empirisk grunnlag for suksess er påvist for de intervensjonene som har vært spesifikt rettet mot en spesiell selvmordsmetode, for eksempel hengning i psykiatriske avdelinger eller forgiftning ved hjelp av aspirin og paracetamol (H awton et al., 2004).

Figur 4: Utvikling i selvmordsraten i England i forhold til målsettingen

Rater for dødsfall som skyldes villet egenskade eller der det er usikkert om skaden er påført med hensikt unntatt 'venter på avgjørelse' i England 1993-2005, og målet for år 2010, for hele befolkningen

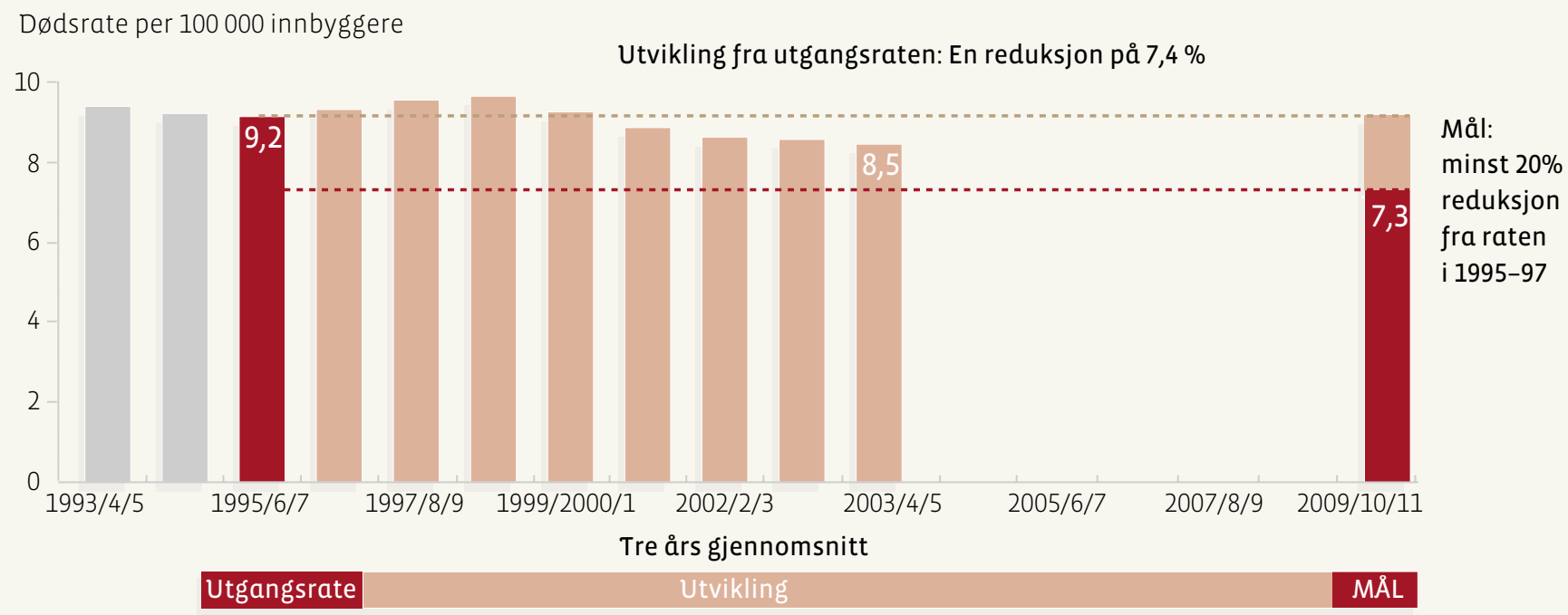


Vi har nå muligheten til å monitorere like grundig effekten av å trekke tilbake co-proxamol siden dette preparatet nå er mindre tilgjengelig.

Det er mye vanskeligere å måle virkningen av tiltak rettet mot spesielle etniske grupper eller personer med annen enn heteroseksuell legning, hvor det ikke er noen rutinemessig registrering av data. D et pågår en politisk debatt på høyeste nivå rundt ny lovgivning for rettsmedisinerne. Det er et åpent spørsmål om dette vil gjøre selvmordsforebyggende arbeid lettere eller ikke.

Det er også vanskelig å måle resultatet av mer generelle intervensjoner som har som mål å fremme den psykiske helsen i hele befolkningen, eller av arbeidet med media fordi det er vanskelig å ta høyde for samtidige endringer i variabler som for eksempel økonomiske forhold, arbeidsledighetsraten for ungdom, og tilfeldige innspill fra høyt profilerte offentlige personer som står frem med sin psykiske lidelse: Som aktuelle eksempler på dette i England kan vi nevne statsministerens tidligere medierådgiver A listair C ampbell, skuespiller Stephen Fry og bokseren Frank Bruno.

Dette betyr ikke at arbeidet på disse områdene ikke er umaken verd. $\mathrm{Vi}$ må bare være ærlige på at det noen ganger ikke er mulig å vite med sikkerhet om en observert forbedring kan knyttes til innsatsen til det nasjonale programmet for selvmordsforebygging på noen måte. Dette gjelder også den oppmuntrende utviklingen i selvmordsratene i England, som har nådd sitt laveste nivå noensinne.

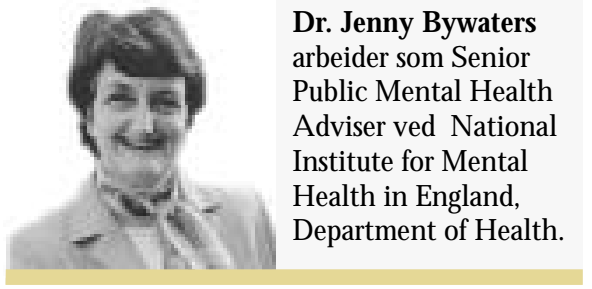

Takk til Sue G raves, Simon Lewry og Peter A bbott fra

"D epartment of $\mathrm{H}$ ealth $\mathrm{C}$ entral $\mathrm{M}$ onitoring U nit" for hijelp med det statistiske materialet.

\section{Referanser}

A mos T, A ppleby L, and Kiernan K. (2001). C hanges in rate of suicide by car exhaust asphyxiation in England and W ales. Psychological M edicine, 31, 935-939.

A ppleby A, Shaw J, A mos T, M CD onnell R, Davies S et al. (1999). Safer Services: $\mathrm{N}$ ational $\mathrm{C}$ onfidential Inquiry into Suicide and $\mathrm{H}$ omicide by people with mental illness. Department of $\mathrm{H}$ ealth. London.

A ppleby L, Shaw J, Sherratt J, A mos T, Robinson J, M CDonnell R, M CC ann K, Parsons R, Burns J, Bickley H, Kiernan K, W ren J, H unt I, Davies $S$ and $H$ arris C. (2001). Safety First: Five Year R eport of the $\mathbf{N}$ ational C onfidential Inquiry into Suicide and $\mathrm{H}$ omicide by people with mental illness. Department of $\mathrm{H}$ ealth. London.

DH . (1999a). Saving Lives: O ur H ealthier N ation. Department of H ealth. London. The Stationery O ffice.

DH . (1999b). N ational Service Framework for M ental H ealth: M odern standards and service models. Department of $\mathrm{H}$ ealth. London.

DH . (2000). A n Organisation with a Memory. Report of an expert group on learning from adverse events in the N H S chaired by the C hief Medical 0 fficer. Department of $\mathrm{H}$ ealth. London.

DH . (2002). N ational Suicide Prevention Strategy for England. Department of $\mathrm{H}$ ealth. London.

DH . (2006a). $\mathbf{O}$ ur $\mathrm{H}$ ealth, $\mathbf{O}$ ur $\mathrm{C}$ are, $\mathbf{O}$ ur Say: a new direction for community services. Department of $\mathrm{H}$ ealth. London.
DH . (2006b). $\mathbf{H}$ elp is at $\mathbf{H}$ and: a resource for people bereaved by suicide and other sudden traumatic death. Department of $\mathrm{H}$ ealth. London.

Duffy D., Ryan T., and Purdy R. (2003). Preventing Suicide: a toolkit for mental health services. $\mathrm{N}$ ational Institute for $\mathrm{M}$ ental $\mathrm{H}$ ealth in England. Department of $\mathrm{H}$ ealth.

H awton K, Zahl D and W eatherall R. (2003a). Suicide following deliberate selfharm: long-term follow-up of patients who presented to a general hospital. British Journal of Psychiatry, 182, 537-542.

H awton K , Simkin S, Deeks J.J. (2003b). C o-proxamol and suicide: a study of national mortality statistics and local non-fatal self-poisonings. British M edical Journal, 326, 1006-1008.

H awton K, Simkin S, Deeks J, C ooper J, Johnston A, W aters K, A rundel $M$, Bernal W, G unson B, H udson M, Suri D, Simpson K. (2004). U K legislation on analgesic packs: before and after study of long term effects on poisonings. British M edical Journal, 329, 1076-1079.

$\mathrm{N}$ ational $\mathrm{C}$ onfidential Inquiry into Suicide and $\mathrm{H}$ omicide by people with mental illness. (2006). Avoidable D eaths: five year report of the national confidential inquiry into suicide and homicide by people with mental illness. The U niversity of $M$ anchester.

NICE. (2004). Self-harm: the short-term physical and psychological management and secondary prevention of self-harm in primary and secondary care. G uideline 16. $\mathrm{N}$ ational Institute for $\mathrm{H}$ ealth and $\mathrm{Clinical}$ Excellence.

N IM HE. (2005a). N ational Suicide Prevention Strategy for England: A nnual R eport on Progress 2004. N ational Institute for $\mathrm{M}$ ental $\mathrm{H}$ ealth in England

N IM HE. (2005b). M aking It Possible: Improving M ental H ealth and W ell-being in England. $\mathrm{N}$ ational Institute for $\mathrm{M}$ ental $\mathrm{H}$ ealth in England $\mathrm{C}$ are Services Improvement Partnership. Department of $\mathrm{H}$ ealth.

N IM HE. (2006a). N ational Suicide Prevention Strategy for England: A nnual R eport on Progress 2005. N ational Institute for M ental H ealth in England. $\mathrm{C}$ are Services Improvement Partnership. Department of $\mathrm{H}$ ealth.

N IM HE. (2006b). R eaching 0 ut: Evaluation of three mental health promotion pilots to reduce suicide amongst young men. C are Services I mprovement Partnership. Department of $\mathrm{H}$ ealth.

N IM HE. (2006C). Suicide A udit in Primary C are Trust localities. N ational Institute for $\mathrm{M}$ ental $\mathrm{H}$ ealth in England. $\mathrm{C}$ are Services Improvement Partnership. Department of $\mathrm{H}$ ealth.

N IM HE. (2006d). G uidance on action to be taken at suicide hotspots. N ational Institute for M ental H ealth in England C are Services Improvement Partnership. Department of $\mathrm{H}$ ealth.

Press C omplaints C ommission. (2006). Editors C ode of Practice. H entet 26. january 2007 fra http://www.pcc.org.uk

(A rtikkelen er oversatt av $\mathrm{K}$ ari $\mathrm{H}$ elene $\mathrm{H}$ estvik.)

\section{Ny bok \\ A nbjørg 0 hnstad og \\ Kirsti Malterud (red.) \\ Lesbiske og homofile i møte \\ med helse- og sosialtenesta \\ 0 slo: Samlaget, 2006. - $183 \mathrm{~s}$. ISBN 82-521-6574-5}

Boka handlar mellom anna om identitet, sjølvmord, transseksualitet, haldningar i faglitteraturen helsesøstre og seksualopplysning, legen og møtet med homofile og lesbiske pasientar, HIV /A ids og familieterapi for homoseksuelle familiar. Boka er nyttig for legar, psykologar, familieterapeutar, helse- og sosialarbeidarar og andre utan spesielle forkunnskapar om homoseksualitet.

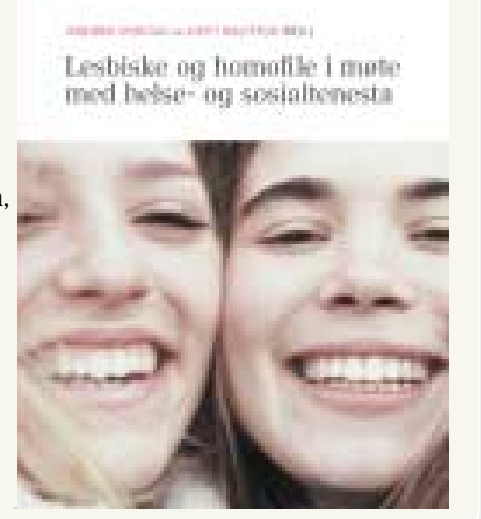

